Article

\title{
Nickel Nanowires: Synthesis, Characterization and Application as Effective Catalysts for the Reduction of Nitroarenes
}

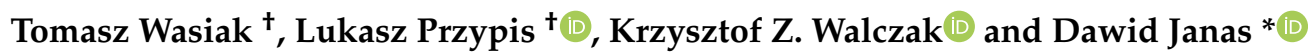 \\ Department of Organic Chemistry, Bioorganic Chemistry and Biotechnology, Silesian University of Technology, \\ B. Krzywoustego 4, 44-100 Gliwice, Poland; tomawas793@student.polsl.pl (T.W.); Lukasz.Przypis@polsl.pl (L.P.); \\ Krzysztof.Walczak@polsl.pl (K.Z.W.) \\ * Correspondence: Dawid.Janas@polsl.pl; Tel.: +48-32-237-10-82 \\ + These authors made equal contributions to the work.
}

Received: 28 October 2018; Accepted: 16 November 2018; Published: 20 November 2018

\begin{abstract}
We have demonstrated a convenient method of synthesizing nickel nanowires (NiNWs), which could be easily tuned to produce materials with a carefully defined nanostructure. By varying the concentration of the Ni precursor, $\mathrm{pH}$ of the medium or reaction temperature, we directly affected the diameter of the formed product as well as the yield of the process. The obtained material consisted of straight bundles of NiNWs, which revealed powerful catalytic action for the reduction of nitroarenes to appropriate amine derivatives. A selection of substrates were employed and all of them were successfully converted into the corresponding aromatic amine despite the presence of different substituents on the aromatic ring with high yields, even in large scale reactions. The results showed that NiNW-based catalysts could constitute efficient catalytic systems for the synthesis of aryl amines at industrial levels.
\end{abstract}

Keywords: nickel nanowires; synthesis; catalytic properties; reduction of nitroarenes

\section{Introduction}

The discovery of the possibility to create materials with nanoscopic precision has opened another chapter in the history of technology for mankind. We have learned that regular chemical elements, which we have known about for a long time, can have a wide spectrum of previously unknown properties if they take the form of a nanodot, nanotube, nanowire, nanosheet, etc. Moreover, these so-called nanomaterials have often been found to outperform the electrical, thermal, mechanical, or other properties of their corresponding bulk materials.

Nickel nanowires (NiNWs) in particular have emerged as a promising material because of their electrical [1,2], thermal [3,4], and magnetic properties [5-7]. Fundamental research on this topic has already led to the development of prototypes for the application of NiNWs for body motion sensing [8], data storage [9], or bioanalysis [10]. Interestingly, the material has only been explored from the catalytic point of view to a very limited extent. For instance, it has been reported as a successful catalyst for promoting the steam reforming of ethanol [11], partial oxidation of methane to syngas [12], or urea electro-oxidation [13]. This is surprising because recent trends in research regarding the catalytic reaction with transition metals has focused on nickel [14-18]. It is an attractive metal for catalysis since it can adopt a flexible number of oxidation states, $\mathrm{Ni}(-\mathrm{I}), \mathrm{Ni}(0), \mathrm{Ni}(\mathrm{I}), \mathrm{Ni}(\mathrm{II}), \mathrm{Ni}(\mathrm{III}), \mathrm{Ni}(\mathrm{IV})$, offering unique reactivity pathways [19-21].

In our study, we focused on the usage of NiNW as an effective catalyst in the reduction of nitroarenes to anilines. This transformation is of great importance for the chemical industry. 
Anilines are among the most important precursors necessary for the production of dyestuffs and pharmaceuticals in the chemical industry. The industrial production of functionalized anilines mainly depends on the non-catalytic reduction of nitroarenes using stoichiometric reducing agents such as sodium hydrosulfite, iron, tin, or zinc in ammonium hydroxide [22-25]. Such processes have major disadvantages like poor selectivity and the generation of toxic wastes. Therefore, the development of a more efficient, selective, and environmentally friendly process to produce anilines is important for both fundamental studies and industrial applications. Catalytic hydrogenation using precious metals such as $\mathrm{Rh}, \mathrm{Pd}, \mathrm{Ru}$, and $\mathrm{Pt}$ as the preferred choice is still not attractive because the cost of producing the catalyst is too expensive. Therefore, the development of a non-noble low cost catalyst has become more intensive in the last decade. Among them, nickel is an attractive metal for that transformation.

In this contribution, we present our results of the synthesis of NiNWs for catalytic applications. First, we studied how $\mathrm{pH}$, temperature, and Ni precursor concentration affected the yield and the shape of the final NiNW product. The results showed that the diameter of the NiNW bundles could be significantly influenced by varying the parameters of the synthesis. To demonstrate the catalytic potential of these nanostructures, we employed them for the reduction of nitrobenzene derivatives to corresponding amines. The presented transformations executed in mild conditions with very high yields prove that NiNWs can be potent catalysts for a wider range of chemical reactions.

\section{Results and Discussion}

\subsection{Mechanism and Methodology of NiNW Synthesis}

To probe the reaction mechanism, initial attempts were carried out according to a method by Eluri et al. wherein hydrazine and sodium hydroxide was introduced to the nickel precursor [26]. A total of $5 \mathrm{~mL}$ of $0.1 \mathrm{M} \mathrm{NiCl}_{2}$ solution in ethylene glycol (EG) was heated up to $60{ }^{\circ} \mathrm{C}$. Then, $0.5 \mathrm{~mL}$ of $\mathrm{N}_{2} \mathrm{H}_{4}$ (aq.) and $1.5 \mathrm{~mL}$ of $0.1 \mathrm{NaOH}$ were added to the beaker. Heating of the reaction mixture led to the formation of a blue precipitate (nickel hydrazine complexes) according to the following transformation.

$$
2 \mathrm{~N}_{2} \mathrm{H}_{5} \mathrm{OH}+\mathrm{NiCl}_{2} \rightarrow\left[\mathrm{Ni}\left(\mathrm{N}_{2} \mathrm{H}_{4}\right)_{2}\right] \mathrm{Cl}_{2}+2 \mathrm{H}_{2} \mathrm{O}
$$

This complex of paramagnetic $\mathrm{Ni}^{2+}$ can then arrange along the magnetic field and react in a stepwise fashion to yield a protonanowire [27]. For that to occur at an appreciable time scale, the temperature has to be increased. After increasing the temperature beyond $100{ }^{\circ} \mathrm{C}$ (and adding a further $6 \mathrm{~mL}$ of $0.1 \mathrm{M} \mathrm{NaOH}$ ), the precipitate started to darken and reached a greyish color after a couple of minutes, which indicated the successful reduction of nickel ions to metallic nickel by the hydrothermal treatment. The mechanism of the reaction is as follows [26]:

$$
\begin{gathered}
{\left[\mathrm{Ni}\left(\mathrm{N}_{2} \mathrm{H}_{4}\right)_{2}\right] \mathrm{Cl}_{2}+2 \mathrm{NaOH} \rightarrow \mathrm{Ni}(\mathrm{OH})_{2}+2 \mathrm{~N}_{2} \mathrm{H}_{4}+2 \mathrm{NaCl}} \\
\mathrm{HOCH}_{2}-\mathrm{CH}_{2} \mathrm{OH}+\mathrm{Ni}(\mathrm{OH})_{2} \rightarrow \mathrm{Ni}(\mathrm{COOH})_{2}+6 \mathrm{H}^{+}+6 \mathrm{e} \\
2 \mathrm{Ni}(\mathrm{COOH})_{2}+4 \mathrm{OH}^{-} \rightarrow 2 \mathrm{Ni}\left(\mathrm{HCO}_{3}\right)_{2}+2 \mathrm{H}_{2} \\
2 \mathrm{Ni}^{2+}+4 \mathrm{OH}^{-}+\mathrm{N}_{2} \mathrm{H}_{4} \rightarrow 2 \mathrm{Ni}+\mathrm{N}_{2}+4 \mathrm{H}_{2} \mathrm{O}
\end{gathered}
$$

Although the reaction eventually did lead to NiNWs, all of the obtained products were contaminated with the aforementioned blue precipitate. Washing the product with copious amounts of water and isopropanol did not remove the contaminant. Furthermore, the dimethylglyoxime test was used to detect nickel ions gave a bright red color (indicative of the presence of nickel bis(dimethylglyoximate) in the dispersed product), which confirmed that the reaction was incomplete. As a consequence, this synthesis route was abandoned.

We decided to adapt and tune the parameters of the published technique, in which water was essentially eliminated (except for the $\mathrm{N}_{2} \mathrm{H}_{4}$ solvation water) and ethylene glycol was used instead as the reaction medium $[26,28]$. This approach afforded NiNWs, which more readily aligned in the 
magnetic field (compared to products prepared by the previous method) and no signs of adulteration were observed.

\subsection{The Influence of Reaction Conditions on the Microstructure}

\subsubsection{Temperature}

Temperature often has a significant effect on the reaction rates according to the Arrhenius relation and this situation is no different in the case of NiNW synthesis. However, the precise quantification of this influence is difficult because, as we found, NiNW synthesis has an exothermic nature. Combination of the nickel precursor with a reducing agent under basic conditions causes a notable increase in temperature by more than $10^{\circ} \mathrm{C}$ (as measured by an on-line thermocouple). We attempted to carry out this process at the starting temperatures of $80^{\circ} \mathrm{C}, 100^{\circ} \mathrm{C}$, and $120^{\circ} \mathrm{C}$. Low temperature of the reaction mixture $\left(80^{\circ} \mathrm{C}\right)$ resulted in the evident appearance of the blue precipitate, part of which was eventually converted into NiNWs. By increasing the temperature to $100{ }^{\circ} \mathrm{C}$, we were able to significantly reduce the life time of the blue precipitate. It has to be noted that the increase in temperature accelerated the unwanted evaporation of hydrazine, so a trade-off has to be established. We postulate that the optimum temperature is $100{ }^{\circ} \mathrm{C}$.

As shown in Table 1 and Figure 1, the temperature had a very strong effect on the yield of the process and the diameter of the obtained NiNW bundles. The presence of the blue precipitate at $80^{\circ} \mathrm{C}$, indicative of contamination, was directly reflected in the yield of the final product. After purification, the yield of the product was just $33 \%$. With an increase in temperature, the NiNW synthesis not only occurs much faster, but its yield can be increased up to $97 \%$ by establishing appropriate thermodynamic conditions. Furthermore, the higher the reaction temperature, the smaller the diameter of the obtained NiNW bundles. It appears that an increase in thermal energy favors the elongation of NiNWs rather than growth in the radial direction.

Table 1. The influence of reaction temperature on the product parameters.

\begin{tabular}{ccccccc}
\hline & \multicolumn{3}{c}{ Reaction Conditions } & \multicolumn{2}{c}{ Product Parameters } \\
\hline $\mathbf{V}_{\mathbf{N a O H}}[\mathbf{m L}]$ & $\mathbf{V}_{\mathbf{N 2 H 4}}[\mathbf{m L}]$ & $\mathbf{V}_{\mathbf{N i C l 2}}[\mathbf{m L}]$ & $\mathbf{C}_{\mathbf{N i C l 2}}[\mathbf{M}]$ & $\mathbf{T}\left[{ }^{\circ} \mathbf{C}\right]$ & Yield [\%] & $\begin{array}{c}\text { Bundle } \\
\text { Diameter [nm] }\end{array}$ \\
\hline 70 & 20 & 10 & 0.1 & 80 & 33 & $655 \pm 122$ \\
70 & 20 & 10 & 0.1 & 100 & 85 & $451 \pm 87$ \\
70 & 20 & 10 & 0.1 & 120 & 97 & $335 \pm 121$ \\
\hline
\end{tabular}
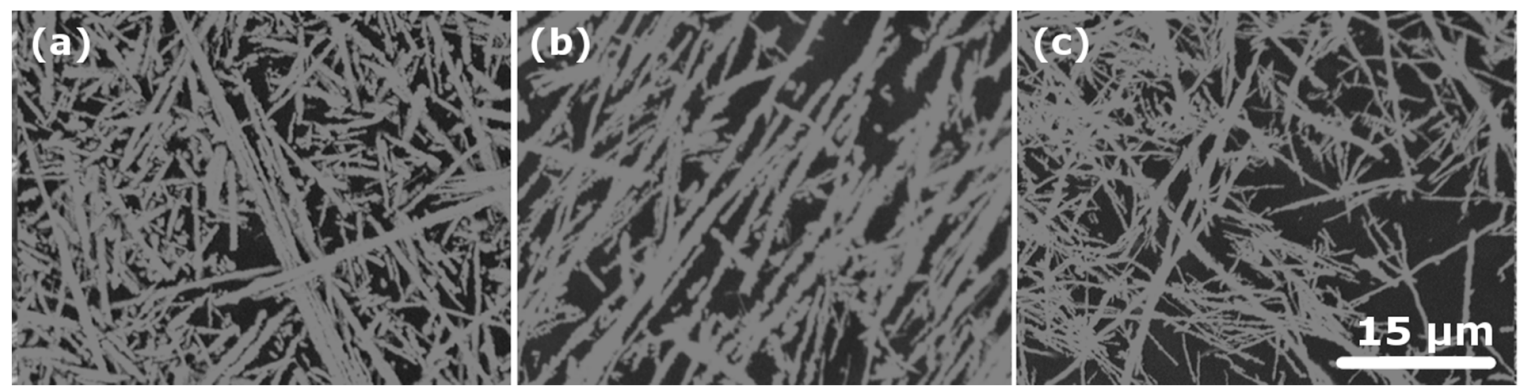

Figure 1. Micrographs of the NiNWs formed at different temperatures: (a) $80{ }^{\circ} \mathrm{C}$, (b) $100{ }^{\circ} \mathrm{C}$ and (c) $120{ }^{\circ} \mathrm{C}$.

\subsection{2. $\mathrm{pH}$}

When looking at the mechanism of the NiNW formation, it is evident that the $\mathrm{pH}$ of the reaction medium plays a significant role. We varied the content of hydroxyl anions by changing the volume of the added 0.1 M NaOH solution in EG. With an increase in $\left[\mathrm{OH}^{-}\right]$, we observed a decrease in the NiNW bundle diameter from $426 \pm 91$ down to $306 \pm 57 \mathrm{~nm}$ (Table 2). This effect is very similar to the 
capping action of polyvinylpyrrolidone in the course of AgNW formation [29]. In that case, the polymer wrapped around the nascent NW and caused the preferential addition of metal nanoclusters from the front, which caused an elongation of NW instead of an increase in bundle diameter. It is possible that the more hydroxyl anions in the medium, the finer the building blocks of NiNWs because under such circumstances, they can be more easily hydrated and thus separated from each other. Increasing the $\mathrm{pH}$ improved the yield from $51 \%(35 \mathrm{~mL} \mathrm{NaOH})$ to $85 \%(70 \mathrm{~mL} \mathrm{NaOH}$, Table 1, entry 2) before it decreased to $68 \%(100 \mathrm{~mL} \mathrm{NaOH})$, so there appears to be a sweet spot, at which the synthesis is most effective. The micrographs of the products are shown in Figure 2. The smaller bundle diameter NiNWs appear to be more tightly packed.

Table 2. The influence of $\mathrm{pH}$ on the product parameters.

\begin{tabular}{ccccccc}
\hline & \multicolumn{3}{c}{ Reaction Conditions } & \multicolumn{2}{c}{ Product Parameters } \\
\hline $\mathbf{V}_{\mathbf{N a O H}}[\mathrm{mL}]$ & $\mathbf{V}_{\mathbf{N 2 H 4}}[\mathrm{mL}]$ & $\mathbf{V}_{\mathbf{N i C l} \text { [ }[\mathbf{m L}]}$ & $\mathbf{C}_{\mathbf{N i C l} \text { [ }}[\mathbf{M}]$ & $\mathbf{T}\left[{ }^{\circ} \mathbf{C}\right]$ & Yield [\%] & $\begin{array}{c}\text { Bundle } \\
\text { Diameter [nm] }\end{array}$ \\
\hline 35 & 20 & 10 & 0.1 & 100 & 51 & $426 \pm 91$ \\
50 & 20 & 10 & 0.1 & 100 & 51 & $387 \pm 65$ \\
100 & 20 & 10 & 0.1 & 100 & 68 & $306 \pm 57$ \\
\hline
\end{tabular}

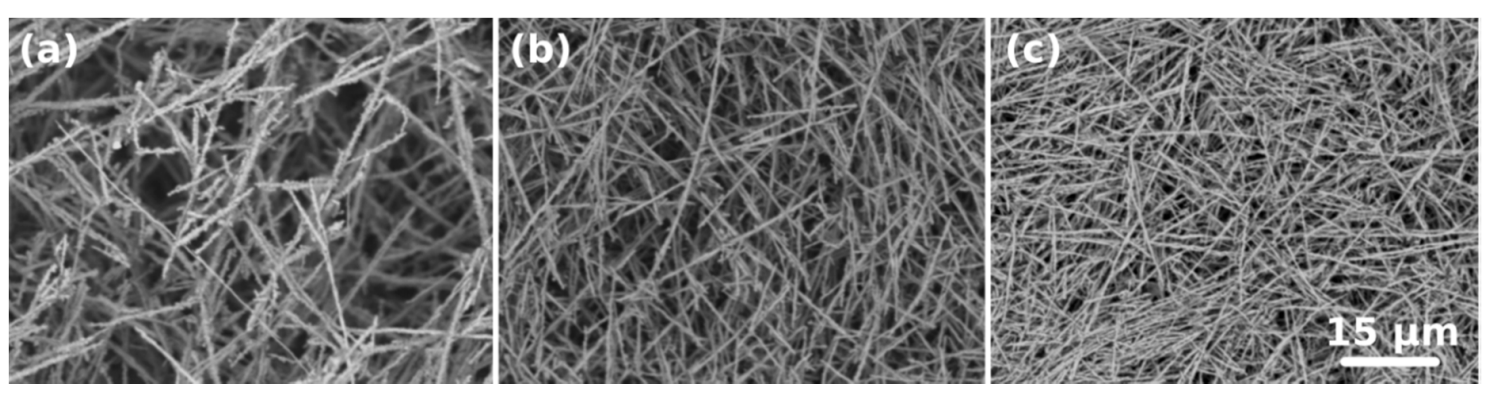

Figure 2. Micrographs of the NiNWs formed after the addition of a selected volume of $0.1 \mathrm{M} \mathrm{NaOH}$ : (a) $35 \mathrm{~mL}$, (b) $50 \mathrm{~mL}$, and (c) $100 \mathrm{~mL}$.

\subsubsection{NiNW Precursor Concentration}

We found that the nickel concentration had a significant influence on the bundle diameter of the synthesized NiNWs. The higher the Ni concentration, the larger the bundle diameter of the produced NiNWs (Figure 3). It appears as if under high concentration conditions, the nucleating NiNW seeds grow larger and extrude NWs of the corresponding geometry. Moreover, high Ni ion concentration makes the addition of $\mathrm{Ni}$ from the radial direction more preferable when compared with the desired addition from the front. A decrease in $\mathrm{Ni}$ concentration mitigates the problem of this side reaction and the bundle diameter of the formed NWs decreases accordingly. By lowering the concentration of $\mathrm{Ni}$ ions from $0.5 \mathrm{M}$ to $0.01 \mathrm{M}$, we were able to reduce the bundle diameter from $498 \pm 103$ to $316 \pm 53 \mathrm{~nm}$ (Table 3). Moreover, the NiNW precursor concentration did not appear to have an effect on the yield of the process.

Table 3. The influence of NiNW precursor concentration on the product parameters.

\begin{tabular}{ccccccc}
\hline \multicolumn{3}{c}{ Reaction Conditions } & \multicolumn{2}{c}{ Product Parameters } \\
\hline $\mathbf{V}_{\mathbf{N a O H}}[\mathbf{m L}]$ & $\mathbf{V}_{\mathbf{N 2 H 4}}[\mathbf{m L}]$ & $\mathbf{V}_{\mathbf{N i C l} \mathbf{2}}[\mathbf{m L}]$ & $\mathbf{C}_{\mathbf{N i C l} 2}[\mathbf{M}]$ & ${\mathbf{T ~}\left[{ }^{\circ} \mathbf{C}\right]}$ & Yield [\%] & $\begin{array}{c}\text { Bundle } \\
\text { Diameter [nm] }\end{array}$ \\
\hline 175 & 50 & 5 & 0.5 & 100 & 77 & $498 \pm 103$ \\
175 & 50 & 25 & 0.1 & 100 & 85 & $451 \pm 87$ \\
175 & 50 & 50 & 0.050 & 100 & 95 & $363 \pm 55$ \\
175 & 50 & 100 & 0.025 & 100 & 95 & $354 \pm 65$ \\
175 & 50 & 250 & 0.010 & 100 & 88 & $316 \pm 53$ \\
\hline
\end{tabular}




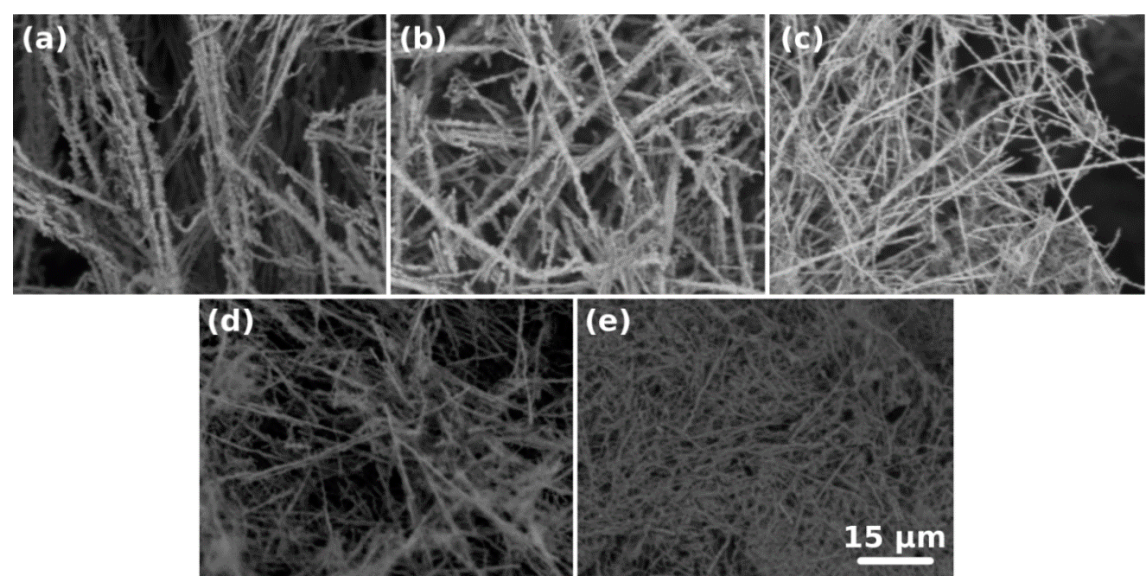

Figure 3. Micrographs of the NiNWs formed after the addition of a selected volume and concentration of $0.1 \mathrm{M} \mathrm{NiCl}_{2}$ : (a) $5 \mathrm{~mL} / 0.5 \mathrm{M}$, (b) $25 \mathrm{~mL} / 0.1 \mathrm{M}$, (c) $50 \mathrm{~mL} / 0.050 \mathrm{M}$, (d) $100 \mathrm{~mL} / 0.025 \mathrm{M}$, and (e) $250 \mathrm{~mL} / 0.010 \mathrm{M}$.

\subsubsection{Alternative Reducing Agents}

As the mechanism of the reaction shows, the addition of hydrazine is crucial because it enables the formation of some crucial intermediate nickel complexes. However, the use of hydrazine as a reducing agent is inconvenient because it tends to evaporate from the mixture, which must kept at a high temperature for the reaction to take place at an appreciable rate. We explored a selection of nitrogen-bearing weak reducing agents as possible alternatives: ethylenediamine [30], aniline [31], and ammonia [32]. None of these reductants, however, enabled the synthesis of NiNWs ( $0 \%$ yield). After their addition, we obtained a violet solution, dark brown solution, and white precipitate, respectively.

We suspected that hydrazine as a ligand is somehow important for the reaction course (and also has a sufficiently potent reducing power), so we decided to try hydrazine sulfate as the alternative. Hydazine sulfate is a solid at room temperature and since we operated in basic conditions, free hydrazine could be liberated in the controlled fashion, when needed. This would alleviate the problem of hydrazine evaporation during the heating up of the reaction mixture. Although the reaction did lead to NiNWs, very low yield (ca. 5\%) and a high degree of contamination makes it an unviable route towards these nanostructures.

\subsection{NW Composition}

Crystallographic studies showed that the NiNWs resembled very much regular Ni (Figure 4). Reflections from (111), (200), (220) and (311) planes were observed. We did not detect signs of NiO on the surface.

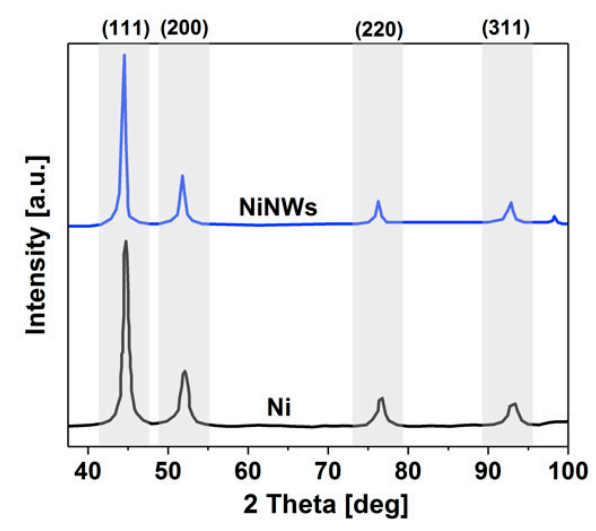

Figure 4. XRD patterns of NiNWs and Ni reference. 


\subsection{Catalytic Performance}

After satisfactory characterization, the catalyst NiNW (of mean $363 \pm 55 \mathrm{~nm}$ bundle diameter) was further applied in the targeted selective reduction of nitroarenes. Although several methods have been reported for the reduction of nitrobenzene derivatives, they generally require expensive catalysts using precious metals like $\mathrm{Rh}, \mathrm{Pd}, \mathrm{Ru}$, and $\mathrm{Pt}$ and need an extended time period for complete conversion. The analysis in Table 4 shows that NiNWs are very attractive from the financial point of view when compared with other routinely employed catalysts available on the market. The cost of a NiNW catalyst is more than four times lower than the price of $\mathrm{Pd} / \mathrm{C}, \mathrm{Rh} / \mathrm{C}$, or Pt/C (all 5\% mol).

Table 4. Comparison of NiNWs and other traditional catalytic systems used for reduction of nitroarenes ${ }^{a}$.

\begin{tabular}{ccccccc}
\hline $\begin{array}{c}\text { Catalyst } \\
\text { [\% mol] }\end{array}$ & $\begin{array}{c}\text { Equation of } \\
\mathbf{N}_{\mathbf{2}} \mathbf{H}_{\mathbf{4}}{ }^{*} \mathbf{H}_{\mathbf{2}} \mathbf{O}\end{array}$ & $\begin{array}{c}\text { Temp. } \\
{\left[{ }^{\circ} \mathbf{C}\right]}\end{array}$ & $\begin{array}{c}\text { Time } \\
{[\mathbf{h}]}\end{array}$ & $\begin{array}{c}\text { Yield } \\
{[\%]}\end{array}$ & $\begin{array}{c}\text { Cost of Catalyst for } \\
\text { Reduction of } \mathbf{1} \text { mol of } \\
\text { 4-bromonitrobenzene [\$] }\end{array}$ & Ref. \\
\hline $\mathrm{Pd} / \mathrm{C} \mathrm{5 \%}$ & 10.0 & 90 & 0.25 & 92 & 410 & {$[33]$} \\
$\mathrm{Rh} / \mathrm{C} 5 \%$ & 1.0 & 40 & 3.0 & 90 & 290 & {$[34]$} \\
$\mathrm{Pt} / \mathrm{C} 5 \%$ & 10.0 & 85 & 1.0 & 95 & 520 & {$[35]$} \\
NiNWs & 10.0 & 90 & 3.5 & 96 & 64 & This work \\
\hline
\end{tabular}

a Price for $\mathrm{Pd} / \mathrm{C}, \mathrm{Rh} / \mathrm{C}$, and $\mathrm{Pt} / \mathrm{C}$ was taken from the website of VWR International. For NiNWs, the cost of precursors was also taken from the same vendor and the price of the final NiNW product was calculated based on the results of this work. The data have been normalized to the cost of the catalyst for the reduction of $1 \mathrm{~mol}$ of 4 nitrobenzene (experimental details in the referenced publications) and is presented in US dollars.

In the present work, we developed a mild reduction procedure that used a small amount of a low-cost non-noble catalyst (NiNW), followed with a simple work-up protocol. Initially, the reduction reaction was performed using 4-nitrotoluene as the model substrate with hydrazine hydrate as the hydrogen source at $65{ }^{\circ} \mathrm{C}$ (Table 5). After stirring for $3 \mathrm{~h}$ with the NiNW catalyst, the conversion was $5 \%$. However, both the conversion and selectivity almost reached $100 \%$ after stirring for $4 \mathrm{~h}$ under higher temperature conditions $\left(100^{\circ} \mathrm{C}\right)$. The results demonstrated that the present catalytic system could be used to reduce the nitro group to an amino one. Encouraged by this promising result, we decided to examine the suitability of different reducing agents (sodium borohydride, formic acid, ammonium formate) as hydrogen sources in a reductive catalytic system with our catalyst (Table 5). Simultaneously, we proceeded to optimize the temperature of the reaction by studying the reduction of 4-nitrotoluene. In Table 5, we show the yields of a selected model compound (4-toluidine) obtained using different reducing agents at various temperatures. To our delight, we observed that hydrazine hydrate was the most effective reducing agent (10 mol-excess compared to nitroarenes). This affords a quantitative conversion into 4-toluidine within $3 \mathrm{~h}$ (Table 5, entry 3) with 94\% yield. Hydrazine hydrate is a friendly reducing agent because decomposition produces only gaseous nitrogen and water as by-products. Moreover, no by-products such as azoxy-, azo- or 1,2-diarylhydrazine were detected in the obtained amines (analysis of ${ }^{1} \mathrm{H}$ NMR spectra). Other explored reducing agents did not afford the product in high yield or the reaction did not proceed (indicated with n.r. standing for no reaction) at all, regardless of the temperature conditions employed. 
Table 5. Optimization of the reaction conditions ${ }^{\text {a }}$.

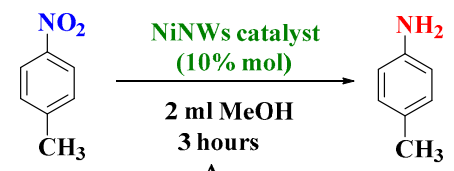

\begin{tabular}{cccc}
\hline No. & {$[\mathbf{H}]$} & Temp. $\left[{ }^{\circ} \mathrm{C}\right]$ & Yield [\%] \\
\hline 1 & $\mathrm{~N}_{2} \mathrm{H}_{4}{ }^{*} \mathrm{H}_{2} \mathrm{O}$ & 65 & 5 \\
2 & $\mathrm{~N}_{2} \mathrm{H}_{4}{ }^{*} \mathrm{H}_{2} \mathrm{O}$ & 75 & 30 \\
3 & $\mathrm{~N}_{2} \mathrm{H}_{4}{ }^{*} \mathrm{H}_{2} \mathrm{O}$ & 90 & 94 \\
4 & $\mathrm{~N}_{2} \mathrm{H}_{4}{ }^{*} \mathrm{H}_{2} \mathrm{O}$ & 100 & 92 \\
5 & $\mathrm{NaBH}_{4}$ & 65 & 10 \\
6 & $\mathrm{NaBH}_{4}$ & 75 & 15 \\
7 & $\mathrm{NaBH}_{4}$ & 90 & 18 \\
8 & $\mathrm{NaBH}$ & 100 & 18 \\
9 & $\mathrm{HCOOH}$ & 65 & n.r. \\
10 & $\mathrm{HCOOH}$ & 75 & n.r. \\
11 & $\mathrm{HCOOH}$ & 90 & n.r. \\
12 & $\mathrm{HCOOH}$ & 100 & 5 \\
13 & $\mathrm{HCOOH}$ & 120 & 31 \\
14 & $\mathrm{NH}_{4} \mathrm{COOH}$ & 65 & n.r. \\
15 & $\mathrm{NH}_{4} \mathrm{COOH}$ & 75 & n.r. \\
16 & $\mathrm{NH}_{4} \mathrm{COOH}$ & 90 & n.r. \\
17 & $\mathrm{NH}_{4} \mathrm{COOH}$ & 100 & n.r \\
18 & $\mathrm{NH}_{4} \mathrm{COOH}$ & 120 & n.r \\
\hline
\end{tabular}

a Reaction conditions: Substituted nitroarenes (2.0 mmol), $\mathrm{N}_{2} \mathrm{H}_{4}{ }^{*} \mathrm{H}_{2} \mathrm{O}(20.0 \mathrm{mmol}), \mathrm{NiNW}$ catalysts $(10 \mathrm{~mol} \% \mathrm{Ni})$, $\mathrm{MeOH}(2 \mathrm{~mL}), 90^{\circ} \mathrm{C}$. Products were isolated and determined by NMR. Optimum reaction conditions are highlighted.

In the next step, a selection of nitro-substrates were examined under the optimized reaction conditions (Table 6). Selective reduction of various substituted nitroaromatics to their corresponding aminoarenes occurred in high yields. Moreover, under our developed protocol, hydrazine exhibited chemoselectivity rather than classical reduction conditions as with hydrogen or sodium borohydride. We did not observe dehalogenation by-reaction of 4-bromonitrobenzene under our procedure with hydrazine and NiNWs.

Table 6. Synthesis of the substituted anilines ${ }^{\mathrm{a}}$.

No.

\footnotetext{
a Reaction conditions: Substituted nitroarenes $(2.0 \mathrm{mmol}), \mathrm{N} 2 \mathrm{H} 4{ }^{*} \mathrm{H} 2 \mathrm{O}(20.0 \mathrm{mmol})$, NiNW catalysts $(10 \mathrm{~mol} \% \mathrm{Ni})$,
} $\mathrm{MeOH}(2 \mathrm{~mL}), 90^{\circ} \mathrm{C}$. Products were isolated and determined by NMR.

In all of the reductions in our protocol, the work-up of anilines was extremely simple. The reaction mixture was diluted using a large amount of ethyl acetate. Then, it was washed twice by water and 
organic solvent was evaporated at diminished pressure. Finally, pure derivatives of anilines were obtained with yields exceeding $90 \%$.

We also tested if this reaction system could be scaled up by one order of magnitude to evaluate its possible commercial potential. 4-nitrobenzoic acid was successfully converted into the corresponding amine with $94 \%$ yield (Supplementary Information). The positive outcome of this experiment at a gram scale is very encouraging because it proves that NiNWs can be used as powerful catalysts already beyond the laboratory scale.

\section{Experimental}

\subsection{Materials and Methods}

To synthesize NiNWs, the following chemicals of analytical grade were employed: nickel chloride hexahydrate (Acros Organics, Geel, Belgium), hydrazine monohydrate (64\%wt, Acros Organics, Geel, Belgium), hydrazine monohydrate ( $50 \% w t$, Acros Organics, Geel, Belgium), formic acid ( $85 \%$ aqueous solution, Acros Organics, Geel, Belgium), ammonium formate (Acros Organics, Geel, Belgium), sodium borohydride (Merck, Darmstadt, Germany), 4-Nitrotoluene (Merck, Darmstadt, Germany), 4-Bromonitrobenzene (Acros Organics, Geel, Belgium), nitrobenzene (Merck, Darmstadt, Germany), 4-Nitrobenzoic acid (Acros Organics, Geel, Belgium), methanol (SureSeal ${ }^{\circledR}$, Acros Organics, Geel, Belgium), ethyl acetate (Chempur, Piekary Slaskie, Poland), ethylene glycol (Chempur, Piekary Slaskie, Poland), sodium bicarbonate (Chempur, Piekary Slaskie, Poland), and sodium hydroxide (Chempur, Piekary Slaskie, Poland).

The standard reaction conditions were as follows. $175 \mathrm{~mL}$ of $0.1 \mathrm{M} \mathrm{NaOH}$ solution in ethylene glycol (EG) was combined with $50 \mathrm{~mL}$ of $50 \%$ wt $\mathrm{N}_{2} \mathrm{H}_{4}$ hydrate and the mixture was heated up to $120^{\circ} \mathrm{C}$. Then, $25 \mathrm{~mL}$ of $0.1 \mathrm{M} \mathrm{NiCl}_{2}$ solution in EG was dripped into the mixture in the presence of a neodymium magnet able to hold $55 \mathrm{~kg}$ of load (kept in another beaker). Immediately formed NiNWs (in the form of a dark grey suspension) were attracted to the magnet. The method is shown in Figure 5. After the reaction, the NiNWs were separated from the liquid medium and washed thoroughly with water and isopropanol. We could not discern the presence of any other obvious sources of contamination such as precipitates of another color. Where indicated in the text, the conditions of the reaction were modified to tune the microstructure of the obtained product.

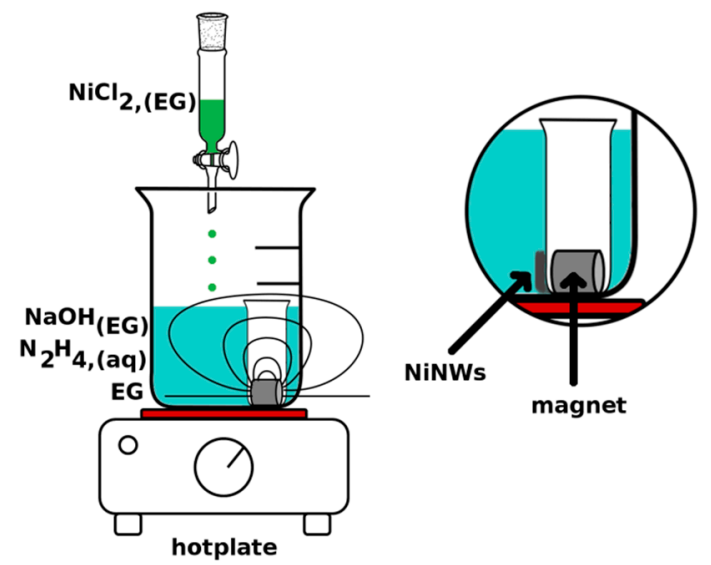

Figure 5. The method of synthesis used in the study. Only a selection of magnetic field lines are shown for the sake of clarity.

To carry out the reduction, the catalyst $(10 \% \mathrm{mmol})$ was placed in a $10 \mathrm{~mL}$ glass reactor (Schlenk tube), followed by the addition of methanol $(2 \mathrm{~mL})$, nitroarene $(1.0 \mathrm{mmol})$, reducing compound, and methanol. Then, the reaction was vigorously stirred for an appropriate time at elevated temperature (details of the synthesis are indicated in the text). 
The microstructure of the material was probed by scanning electron microscopy (SEM) using a HITACHI TM3000 (Tokyo, Japan) with $5 \mathrm{kV}$ acceleration voltage. The results are represented as the diameter of NiNW bundles as observed by SEM and measured using ImageJ software v. 1.52 (University of Wisconsin, UW, USA). To attain the statistical significance, tens of individual bundles were measured each time and the results are shown as mean \pm standard deviation.

The X-ray diffraction (XRD, Philips PW1050, Eindhoven, Netherlands) gauged the chemical identity of the NWs $\left(2 \theta=35-100^{\circ}, 0.05^{\circ}\right.$ step, $2 \mathrm{~s}$ acquisition time).

NMR spectra were recorded at $298 \mathrm{~K}$ on an Agilent-MR NMR (Palo Alto, CA, USA; $400 \mathrm{MHz}$ for $1 \mathrm{~h}$ and at $100.5 \mathrm{MHz}$ for $13^{\circ} \mathrm{C}$ ).

The progress of the reaction was monitored by TLC using silica-gel-coated aluminum plates with a fluorescence indicator (Merck, $\left.\mathrm{SiO}_{2} 60, \mathrm{~F} 254\right)$ and visualized by UV light (254 nm and $365 \mathrm{~nm}$ ) or dipping into an iodine chamber (well-closed chamber with a few crystals of elemental iodine and $10 \mathrm{~g}$ of silica gel).

Melting points (m.p.) were determined with a Boetius apparatus and are uncorrected.

Mass spectrometry were determined with an API 4000Q TRAP tandem mass spectrometer detector equipped with an electrospray ionization (ESI) source (Applied Biosystems/MDS SCIEX, Foster City, CA, USA).

More experimental details can be found in the Supplementary Information.

\subsection{Catalytic Tests}

\subsubsection{General Procedure of Reduction of Nitroarenes}

The appropriate nitrobenzene derivative (1.000 eq.) was added to a Schlenk tube and was dissolved in methanol (each $1 \mathrm{~mL}$ per $1 \mathrm{mmol}$ of nitrobenzene derivative). Next, the loaded nickel nanowires catalyst ( 0.10 eq.) and reaction mixture was stirred at $50{ }^{\circ} \mathrm{C}$. Then, hydrazine hydrate $(100 \%)$ was added slowly with a syringe and subsequently the temperature was raised to $90^{\circ} \mathrm{C}$ (vigorous hydrogen gas evolution was observed). The resulting mixture was stirred for an additional 3 to $4 \mathrm{~h}$ and cooled to room temperature. Then, it was diluted with ethyl acetate (each $15 \mathrm{~mL}$ per $1 \mathrm{mmol}$ of substrate) and washed with saturated sodium carbonate (each $5 \mathrm{~mL}$ per $1 \mathrm{mmol}$ of substrate) and twice with distilled water (each $5 \mathrm{~mL}$ per $1 \mathrm{mmol}$ of substrate). The organic solution was dried over anhydrous $\mathrm{Na}_{2} \mathrm{SO}_{4}$ and evaporated under reduced pressure to give pure aniline derivatives. The purity of the product was sufficient as indicated by NMR spectra analysis.

\subsubsection{Large-Scale Reduction of 4-Nitrobenzoic Acid}

4-Nitrobenzoic acid (3.34 g, $20.0 \mathrm{mmol}$ ) was added to a Schlenk tube and dissolved in anhydrous methanol $\left(20 \mathrm{~mL}\right.$ ) under a $\mathrm{N}_{2}$ atmosphere (Schlenk line). Next, the loaded nickel nanowires catalyst $(118 \mathrm{mg}, 2.0 \mathrm{mmol})$ and reaction mixture was stirred at $50{ }^{\circ} \mathrm{C}$. Then, hydrazine hydrate $(64 \%$ aqueous solution, $11.6 \mathrm{~mL}, 200.0 \mathrm{mmol}$ ) was added slowly with a syringe and subsequently the temperature was raised to $90^{\circ} \mathrm{C}$ (vigorous hydrogen gas evolution was observed). The resulting mixture was stirred for an additional 3 to $4 \mathrm{~h}$ and cooled to room temperature. Then, it was diluted with ethyl acetate $(300 \mathrm{~mL})$ and washed with saturated sodium carbonate $(50 \mathrm{~mL})$ and twice with distilled water $(50 \mathrm{~mL})$. The organic solution was dried over anhydrous $\mathrm{Na}_{2} \mathrm{SO}_{4}$ and evaporated under reduced pressure to give pure 4 -aminobenzoic acid $(2.58 \mathrm{~g}, 18.8 \mathrm{mmol}, 94 \%)$. The purity of the product was sufficient as indicated by NMR spectra analysis.

\subsubsection{Obtained Products}

4-Methylaniline (2a). Following the general procedure above, the title compound (503 $\mathrm{mg}, 94 \%$ ) was isolated as a white solid. Yield: $94 \%$; m.p. $42-43{ }^{\circ} \mathrm{C}$; (lit. mp $\left.=42-43{ }^{\circ} \mathrm{C}\right) ;{ }^{1} \mathrm{H} \mathrm{NMR}(400 \mathrm{MHz}$, DMSO-d6) $\delta 2.12(\mathrm{~s}, 3 \mathrm{H}), 4.75(\mathrm{bs}, 2 \mathrm{H}), 6.46(\mathrm{~d}, \mathrm{~J}=8.2 \mathrm{~Hz}, 2 \mathrm{H}), 6.81(\mathrm{~d}, \mathrm{~J}=8.2 \mathrm{~Hz}, 2 \mathrm{H}) ; 13 \mathrm{C} \mathrm{NMR}$ $\left(151 \mathrm{MHz}, \mathrm{CDCl}_{3}\right) \delta 20.11,114.06,123.96,129.22,146.04 ; \mathrm{MS}(\mathrm{EI}) \mathrm{m} / \mathrm{z}: 108.08[\mathrm{M}+\mathrm{H}]^{+}$. 
Aniline (2b). Following the general procedure above, the title compound (172 $\mathrm{mg}, 92 \%)$ was isolated as a colorless oil. Yield: $92 \%$; b.p. $84{ }^{\circ} \mathrm{C}$ (lit. bp $\left.=84{ }^{\circ} \mathrm{C}\right) ;{ }^{1} \mathrm{H}$ NMR (400 MHz, DMSO-d6) $\delta 4.97$ (bs, 2H), $6.49(\mathrm{tt}, \mathrm{J}=7.3,1.1 \mathrm{~Hz}, 1 \mathrm{H}), 6.56(\mathrm{dd}, \mathrm{J}=8.5,1.1 \mathrm{~Hz}, 2 \mathrm{H}), 7.00(\mathrm{dd}, \mathrm{J}=8.5,7.3 \mathrm{~Hz}, 2 \mathrm{H}) ; 13 \mathrm{C}$

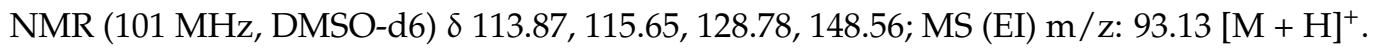

4-Bromoaniline (2c). Following the general procedure above, the title compound ( $495 \mathrm{mg}, 96 \%$ ) was isolated as a white-yellow solid. Yield: $96 \%$; m.p. $62-63{ }^{\circ} \mathrm{C}$; (lit. mp $\left.=62-64{ }^{\circ} \mathrm{C}\right) ;{ }^{1} \mathrm{H}$ NMR $(400 \mathrm{MHz}$, DMSO-d6) $\delta 5.23$ (bs, 2 H), $6.51(\mathrm{~d}, \mathrm{~J}=8.8 \mathrm{~Hz}, 2 \mathrm{H}), 7.12(\mathrm{~d}, \mathrm{~J}=8.8 \mathrm{~Hz}, 2 \mathrm{H}) ; 13 \mathrm{C}$ NMR $(101 \mathrm{MHz}$, DMSO-d6) $\delta$ 106.00, 115.75, 131.28, 148.03; MS (EI) m/z: $172.02[\mathrm{M}+\mathrm{H}]^{+}, 174.02[\mathrm{M}+2+\mathrm{H}]^{+}$.

4-Aminobenzoic acid (2d). Following the general procedure above, the title compound (386 $\mathrm{mg}$, 94\%) was isolated as a white solid. Yield: $94 \%$; m.p. $188-189{ }^{\circ} \mathrm{C}$; (lit. $\mathrm{mp}=186-189^{\circ} \mathrm{C}$ ); ${ }^{1} \mathrm{H}$ NMR (400 MHz, DMSO-d6) $\delta 5.84$ (bs, $2 \mathrm{H}), 6.54$ (d, J = 6.6 Hz, $2 \mathrm{H}), 7.61$ (d, J = 6.7 Hz, $2 \mathrm{H}), 11.39$ (vbs, $1 \mathrm{H})$;

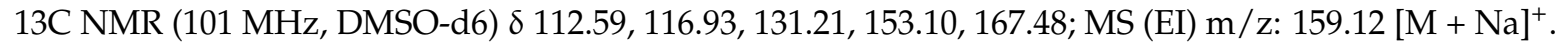

\section{Conclusions}

The nickel nanowires proved to be effective catalysts for the transfer hydrogenation of nitroarenes to the corresponding amine derivatives, using hydrazine as hydrogen donor. The reactions were carried out in mild conditions with very high yield, regardless of the substituents present on the aromatic ring. We also confirmed that these transformations could be executed on an enlarged scale. This indicates that this catalytic system could be useful for transformations at the industrial scale. The presented solution is very attractive as it can substitute traditionally employed metals such as $\mathrm{Rh}, \mathrm{Pd}, \mathrm{Ru}$, and $\mathrm{Pt}$ for catalytic hydrogenation. These species are very expensive in contrast with NiNWs, which can be produced using cheap and widely available precursors. Finally, it is important to mention that NiNWs are stable in the ambient as opposed to other forms of Ni such as Raney nickel, which is pyrophoric, and thus dangerous. Improved safety and high catalytic activity make NiNWs attractive as catalysts for a wide range of chemical transformations.

Supplementary Materials: The following are available online at http://www.mdpi.com/2073-4344/8/11/566/s1. Experimental procedures for the synthesis of amine derivatives, mass spectra, and melting point data as well as copies of NMR spectra $\left({ }^{1} \mathrm{H}\right.$ and $\left.13 \mathrm{C}\right)$.

Author Contributions: T.W., L.P., and D.J. conceived and designed the experiments; T.W. and L.P. performed the experiments; T.W., L.P., K.Z.W., and D.J. analyzed the data; K.Z.W. and D.J. contributed reagents/materials/ analysis tools; T.W., L.P., K.Z.W., and D.J. wrote the paper.

Funding: D.J. and T.W. thank the National Center for Research and Development, Poland (under the Leader program, grant agreement LIDER/1/0001/L-8/16/NCBR/2017). D.J. would also like to acknowledge the Ministry for Science and Higher Education for the scholarship for outstanding young scientists (0388/E-367/STYP/12/2017) and the Rector of the Silesian University of Technology in Gliwice for the Pro-Quality grant (04/020/RGJ18/0057). L.P. and K.Z.W. would also like to thank Silesian University of Technology for financial support of this research (BKM/534/RCh-2/0044).

Conflicts of Interest: There are no conflicts of interest to declare.

\section{References}

1. Lonjon, A.; Laffont, L.; Demont, P.; Dantras, E.; Lacabanne, C. New Highly Conductive Nickel Nanowire-Filled P(VDF-TrFE) Copolymer Nanocomposites: Elaboration and Structural Study. J. Phys. Chem. C 2009, 113, 12002-12006. [CrossRef]

2. Kamalakar, M.V.; Raychaudhuri, A.K. Low temperature electrical transport in ferromagnetic Ni nanowires. Phys. Rev. B 2009, 79, 205417. [CrossRef]

3. Ou, M.N.; Yang, T.J.; Harutyunyan, S.R.; Chen, Y.Y.; Chen, C.D.; Lai, S.J. Electrical and thermal transport in single nickel nanowire. Appl. Phys. Lett. 2008, 92, 063101. [CrossRef]

4. Razeeb, K.M.; Roy, S. Thermal diffusivity of nonfractal and fractal nickel nanowires. J. Appl. Phys. 2008, 103, 084302. [CrossRef]

5. Whitney, T.M.; Searson, P.C.; Jiang, J.S.; Chien, C.L. Fabrication and Magnetic Properties of Arrays of Metallic Nanowires. Science 1993, 261, 1316. [CrossRef] [PubMed] 
6. Lin, S.W.; Chang, S.C.; Liu, R.S.; Hu, S.F.; Jan, N.T. Fabrication and magnetic properties of nickel nanowires. J. Magn. Magn. Mater. 2004, 282, 28-31. [CrossRef]

7. Cortés, A.; Riveros, G.; Palma, J.L.; Denardin, J.C.; Marotti, R.E.; Dalchiele, E.A.; Gómez, H. Single-Crystal Growth of Nickel Nanowires: Influence of Deposition Conditions on Structural and Magnetic Properties. J. Nanosci. Nanotechnol. 2009, 9, 1992-2000. [CrossRef] [PubMed]

8. Wang, S.; Chen, K.; Wang, M.; Li, H.; Chen, G.; Liu, J.; Xu, L.; Jian, Y.; Meng, C.; Zheng, X.; et al. Controllable synthesis of nickel nanowires and its application in high sensitivity, stretchable strain sensor for body motion sensing. J. Mater. Chem. C 2018, 6, 4737-4745. [CrossRef]

9. Samardak, A.S.; Sukovatitsina, E.V.; Ognev, A.V.; Chebotkevich, L.A.; Mahmoodi, R.; Peighambari, S.M.; Hosseini, M.G.; Nasirpouri, F. High-density nickel nanowire arrays for data storage applications. J. Phys. Conf. Ser. 2012, 345, 012011.

10. Pinheiro, P.C.; Sousa, C.T.; Araújo, J.P.; Guiomar, A.J.; Trindade, T. Functionalization of nickel nanowires with a fluorophore aiming at new probes for multimodal bioanalysis. J. Colloid Interface Sci. 2013, 410, 21-26. [PubMed]

11. Hong, X.B. Steam Reforming of Ethanol by a Nickel Nanowire Catalyst. Appl. Mech. Mater. 2014, 651-653, 92-102. [CrossRef]

12. Hong, X.; Wang, Y. Partial oxidation of methane to syngas catalyzed by a nickel nanowire catalyst. J. Nat. Gas Chem. 2009, 18, 98-103. [CrossRef]

13. Yan, W.; Wang, D.; Diaz, L.A.; Botte, G.G. Nickel nanowires as effective catalysts for urea electro-oxidation. Electrochim. Acta 2014, 134, 266-271. [CrossRef]

14. Aditya, T.; Pal, A.; Pal, T. Nitroarene reduction: A trusted model reaction to test nanoparticle catalysts. Chem. Commun. 2015, 51, 9410-9431. [CrossRef] [PubMed]

15. Fernández, G.; Sort, J.; Pleixats, R. Nickel Nanoparticles Stabilized by Trisimidazolium Salts: Synthesis, Characterization and Application as Recyclable Catalysts for the Reduction of Nitroarenes. ChemistrySelect 2018, 3, 8597-8603. [CrossRef]

16. Romanazzi, G.; Fiore, A.M.; Mali, M.; Rizzuti, A.; Leonelli, C.; Nacci, A.; Mastrorilli, P.; Dell'Anna, M.M. Polymer supported Nickel nanoparticles as recyclable catalyst for the reduction of nitroarenes to anilines in aqueous medium. Mol. Catal. 2018, 446,31-38. [CrossRef]

17. Shukla, A.; Singha, R.K.; Sengupta, M.; Sasaki, T.; Pendem, C.; Bal, R. Surfactant-Induced Preparation of Highly Dispersed Ni-Nanoparticles Supported on Nanocrystalline ZrO2 for Chemoselective Reduction of Nitroarenes. ChemistrySelect 2018, 3, 1129-1141. [CrossRef]

18. Yu, C.; Fu, J.; Muzzio, M.; Shen, T.; Su, D.; Zhu, J.; Sun, S. CuNi Nanoparticles Assembled on Graphene for Catalytic Methanolysis of Ammonia Borane and Hydrogenation of Nitro/Nitrile Compounds. Chem. Mater. 2017, 29, 1413-1418. [CrossRef]

19. Cornella, J.; Gómez-Bengoa, E.; Martin, R. Combined Experimental and Theoretical Study on the Reductive Cleavage of Inert C-O Bonds with Silanes: Ruling out a Classical Ni(0)/Ni(II) Catalytic Couple and Evidence for Ni(I) Intermediates. J. Am. Chem. Soc. 2013, 135, 1997-2009. [CrossRef] [PubMed]

20. Tasker, S.Z.; Standley, E.A.; Jamison, T.F. Recent advances in homogeneous nickel catalysis. Nature 2014, 509, 299. [CrossRef] [PubMed]

21. Wilke, G. Contributions to Organo-Nickel Chemistry. Angew. Chem. Int. Ed. 1988, 27, 185-206. [CrossRef]

22. Burawoy, A.; Critchley, J.P. Electronic spectra of organic molecules and their interpretation-V: Effect of terminal groups containing multiple bonds on the K-bands of conjugated systems. Tetrahedron 1959, 5, 340-351. [CrossRef]

23. Kovar, R.F.; Armond, F.E. Ethynyl-Substituted Aromatic Ortho Diamines and Method of Synthesis. U.S. Patent US3,975,444, 19 May 1975.

24. Suchy, M.; Winternitz, P.; Zeller, M. Heterocyclic Compounds. WO Patent WO1991000278, 27 June 1990.

25. Butera, J.A.; Bagli, J.F. N-heteroaralkyl-substituted-1-aryloxy-2-propanolamina and propylamine derivatives possessing class III antiarrhythmic activity. WO Patent WO1991009023, 3 December 1990.

26. Eluri, R.; Paul, B. Synthesis of nickel nanoparticles by hydrazine reduction: Mechanistic study and continuous flow synthesis. J. Nanopart. Res. 2012, 14, 800. [CrossRef]

27. Sun, L.; Chen, Q.; Tang, Y.; Xiong, Y. Formation of one-dimensional nickel wires by chemical reduction of nickel ions under magnetic fields. Chem. Commun. 2007, 2844-2846. [CrossRef] [PubMed] 
28. Zhang, J.; Xiang, W.; Liu, Y.; Hu, M.; Zhao, K. Synthesis of High-Aspect-Ratio Nickel Nanowires by Dropping Method. Nanoscale Res. Lett. 2016, 11, 118. [CrossRef] [PubMed]

29. Liu, B.; Yan, H.; Chen, S.; Guan, Y.; Wu, G.; Jin, R.; Li, L. Stable and Controllable Synthesis of Silver Nanowires for Transparent Conducting Film. Nanoscale Res. Lett. 2017, 12, 212. [CrossRef] [PubMed]

30. Samadaei, F.; Salami-Kalajahi, M.; Roghani-Mamaqani, H.; Banaei, M. A structural study on ethylenediamineand poly(amidoamine)-functionalized graphene oxide: Simultaneous reduction, functionalization, and formation of 3D structure. RSC Adv. 2015, 5, 71835-71843. [CrossRef]

31. Khan, Z.; Hussain, J.I.; Hashmi, A.A.; Al-Thabaiti, S.A. Preparation and characterization of silver nanoparticles using aniline. Arab. J. Chem. 2017, 10, S1506-S1511. [CrossRef]

32. Acke, F.; Skoglundh, M. Comparison between ammonia and propene as the reducing agent in the selective catalytic reduction of NO under lean conditions over Pt black. Appl. Catal. B Environ. 1999, 20, 133-144. [CrossRef]

33. Li, F.; Frett, B.; Li, H. Selective Reduction of Halogenated Nitroarenes with Hydrazine Hydrate in the Presence of Pd/C. Synlett 2014, 25, 1403-1408. [CrossRef] [PubMed]

34. Oxley, P.; Adger, B.; Sasse, M.; Forth, M. N-Acetyl-N-phenylhydroxylamine via Catalytic Transfer Hydrogenation of Nitrobenzene using Hydrazine and Rhodium on Carbon. Org. Synth. 1989, 67, 187.

35. Kuhn, L. Catalytic Reduction with Hydrazine. J. Am. Chem. Soc. 1951, 73, 1510-1512. [CrossRef]

(c) 2018 by the authors. Licensee MDPI, Basel, Switzerland. This article is an open access article distributed under the terms and conditions of the Creative Commons Attribution (CC BY) license (http://creativecommons.org/licenses/by/4.0/). 